\title{
Some Questions and Answers About the Satellite Power System (SPS)
}

January 1980

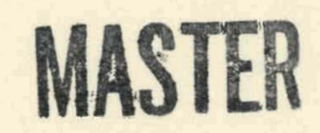

U.S. Department of Energy

Office of Energy Research

Satellite Power System Project Office

\section{DOE /NASA}

Satellite Power System

Concept Development

and

Evaluation Program 


\section{DISCLAIMER}

This report was prepared as an account of work sponsored by an agency of the United States Government. Neither the United States Government nor any agency Thereof, nor any of their employees, makes any warranty, express or implied, or assumes any legal liability or responsibility for the accuracy, completeness, or usefulness of any information, apparatus, product, or process disclosed, or represents that its use would not infringe privately owned rights. Reference herein to any specific commercial product, process, or service by trade name, trademark, manufacturer, or otherwise does not necessarily constitute or imply its endorsement, recommendation, or favoring by the United States Government or any agency thereof. The views and opinions of authors expressed herein do not necessarily state or reflect those of the United States Government or any agency thereof. 


\section{DISCLAIMER}

Portions of this document may be illegible in electronic image products. Images are produced from the best available original document. 
DOE/ER-0049/1

Dist. Category 18

\section{Some Questions and Answers About the Satellite Power System (SPS)}

January 1980

Prepared for:

U.S. Department of Energy

Office of Energy Research

Satellite Power System Project Office

Washington, D.C. 205845

Under Contract No. DE-AC-0179ER-10041

This book was prepared as an accoun or wo DIS CLAIMER

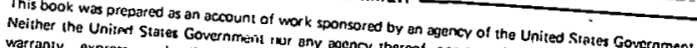

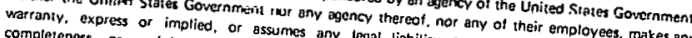

completeness, or usefulness of any information agal liability or responsibitity for the accuracy.

commercial product proces or iniringe privately owned righis Rete process disclosed, or

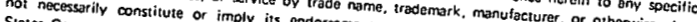

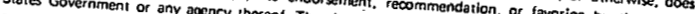

DOE/NASA

Satellite Power System

Concept Development and and

Evaluation Program 


\section{Availabie from:}

National Technical Information, Service (NTIS)

U.S. Department of Commerce

5285 Port Royal Road

Springfield, Virginia 22161

Price: Printed copy: $\$ 4.50$

Microfiche: $\$ 3.00$ 


\section{INTRODUCTION}

The Office of Energy Research, U.S. Department of Energy is evaluating the concept of obtaining significant amounts of electrical energy from space through the Satellite Power System Project Office (SPS PO) formed for that purpose. The SPS PO prepared and is implementing a Concept Development and Evaluation Program plan. The CDEP runs roughly three years (from July 1977 through July 1980) and consists of four primary elements: (1) Systems Definition, (2) Environmental. Assessment, (3) Societal Assessment, and (4) Comparative Assessment. One facet of the Societal Assessment is an investigation of public concerns. To further this investigation, a public outreach experiment was initiated to determine the inital response of three selected interest groups to the SPS, both qualitatively and quantitatively, and to gain some experience for use in future public participation activities.

Three groups were contacted and agreed to participate in the experiment. They were: the Citizens Energy Project (CEP), the Forum for the Advancement of Students in Science and Technology (FASST), and the L-5 Society ( $\mathrm{L}-5)$. They each agreed to condense trenty final SPS reports into approximately four pages each, have them typeset, printed and distributed to 3,000 of their constituents for their review, together with a request that they respond to the parent organization regarding the information presented. In addition, 30 "leaders" were to be contacted by telephone and interviewed to obtain a more detailed response. All responses were summarized and provided to Planning Research Corporation who then solicited the answers from the SPS PO investigator most directly concerned.

The questions and answers are assembled here and will be distributed by the three groups to the individual respondents. Again, reaction to this package will be sought from the recipients and will be carefully considered by the Project office. Each of the three groups is also preparing a report to the Project office detailing their work and results. These, togother with other responses and studies will be used to more effectively involve the public in the SPS Participatory Technology Process. 
FOREWORD

The proper assessment of an advanced technology requires widespread participation from the entire spectrum of interest. Such participation helps to ensure openness, enhance communications, and improve the probability that all major problems are identified and assessed.

A key aspect of the Satellite Power System Concept. Development and Evaluation Program is the evolving Participatory Technology Process. This process attempts to bring together the scientific, public interest, industrial and governmental communities in defining projects, reviewing results and monitoring progress.

Part of the evolving Participatory Technology Process has been a public outreach experiment. This experiment has solicited comments from 9000 individuals, 3000 from each of three diverse public groups. The forty-four composite questions contained in this report, reflecting the concerns of more than 1000 respondents, are one result of the experiment. The questions have been answered by the principal investigators from universities, national laboratories, private contractors and government agencies responsible for specific assessment and research studies. Thus, both the interested individual and the investigator learn of the ideas and concerns of the other. The three public interest groups: Citizens Energy Project, the Foruin for the Advancement of Students in Science and Technology (FASST), and the L-5 Society are to be commended for their interest and quality results.

The Planning Research Corporation has been responsible for implementing and coordinating the experiment. This has been accomplished in a most prnfessional manner.

The individuals who took time to formulate their questions, and the investigators who responded to them have both contributed substantially to the SPS assessment.

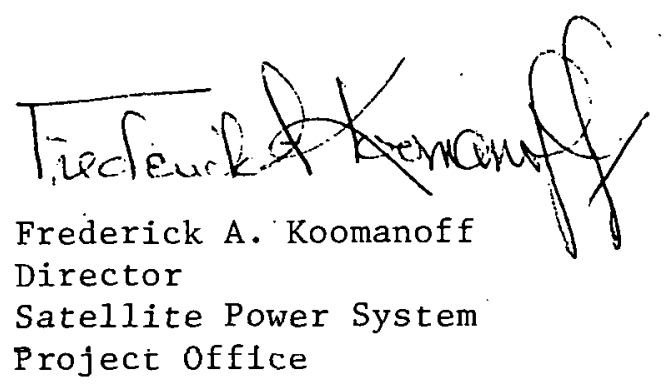




\section{QUESTIONS AND ANSWERS}

I. ABOUT THE SYSTEM

I.1 Will an orbiting satellite the size of SPS be stable at GEO or will it de-orbit like the Skylab and be a potential danger to people on the ground?

The atmospheric density at geostationary orbit (GEO) is so low that synchronous satellites are generally considered to have an indefinite lifetime. However, the SPS would have a much smaller mass to area ratio than any previous satellite at this altitude and thus would be more subject to atmospheric drag. An investigation of orbital decay of the SPS components ${ }^{1}$ found that decay of the satellite over its 30-year. lifetime could be expected to lie between 0.25 and 2500 meters, i.e., less than 1 part in 10,000 in the worst case. Other components at geostationary orbit (construction bases, etc.) would be influenced even less since they have higher mass to area ratios. There are perturbations from other causes such as solar radiation pressure, lunar/solar gravity gradients, and the equatorial ellipticity of the earth. These are somewhat larger than the atmospheric drag effect (although still small) and will be accommodated with planned station-keeping.

A more significant problem is presented by the components in low earth orbit such as the staging base and. the electric orbital transfer vehicle during loading and servicing operations. Both of these components would experience decay of such magnitude that essentially continuous orbit maintenance will be necessary. Loss of orbit maintenance capability would result in irreversible decay in a matter of weeks. Thus, all the subsystems involved (guidance, propulsion, stabilization, pnwer) will l. he highly rediundant and rapid1.y repairable so as to make uncontrolled orbit decay nearly impossible. It will also be necessary to keep sufficient reserve propellent onboard to continue operations in case of launch failure of the resupply vehicles.

Launch vehicle range safety will require that launch failures do not. result in land impact. Since this corresponds to current practice, no unique requirements are foreseen for SPS launch vehicles simply because of their size.

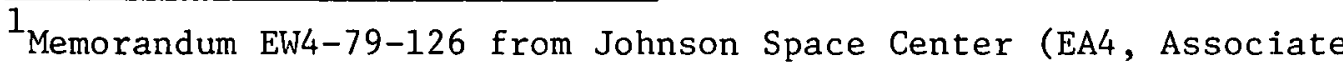
Director for Program Development) to NASA Headquarters (RES-1/ Manager, Space Utilization Systems), Re: SPS System Orbital Decay, 2 August 1979. 
In short, a preliminary investigation of orbital decay of SPS components from launch to geostationary orbit indicates that it is either insignificánt or manageable with current procedures. Additional investigation will be conducted, particularly for launch and the components in low earth orbit as these become better defined.

I.2 How vulnerable is the SPS to partial or total destruction, especially the space segment? For example, do meteor showers pose any threat to the space segment?

The principal area of concern about SPS satellite vulnerability has to do with overt military action. It is highly unlikely that terrorism could pose a direct threat to the satellite on orbit because of its inaccessibility.

The threat of overt military action against the space segment -both satellite and ground-based control system -- is real, although its execution would clearly constitute an act of war. Satellites with hunter-killer capability up to synchronous altitudes, if not operationally avallable today, could be in the near future. Although various hardening measures and self-defense provisions can be implemented, absolute protection of the satellite cannot be assured.

The large scale of the satellite tends to make it somewhat less vulnerable than would be the case otherwise. The large size means that redundant subsystems can readily be provided, and indeed may be mandatory for reliability reasons. The high power level means that many paralleled (redundant) energy circuits can be used in the design. The large scale also means that substantial weapons are needed to do more than partially disable the satellite. It may turn out that because of this large size, the high orbital altitude and the fact of being in a space environuent, nuclear weapons would be the only likely ones with a good probability of achieving assured destruction.

Sabotage of the salellite is a rather unlikely threat. Nlthough preparation of the components for the satellite gives ample opportunity for saboteurs because of the great quantities involved, the nature of the satellite is such that at later stages in its construction these opportunities become more restricted. Parts and materials are subjcctcd to cxtensive inspection and beting because of their end use; this should be quite effective against sabotage. Also, the final assembly is done on orbit by operators who are necessarily carefully screened and selected. 
The vulnerability of the rectenna to overt military action, terrorist attack or sabotage is not greatly different from that of other large utilities. Rectenna operation, however, is not dependent on a critical fuel supply line such as coal or oil, which can be rather easily interdicted, ${ }^{2}$ rendering the rectenna to that extent less vulnerable than other large power plants. Concealment, hardening, protective sheltering and other measures can provide limited protection. The rectenna will be part of an interconnected utility grid, so that the loss of any one station (or satellite) is not necessarily critical.

The large size and inherent redundancy of the satellite would also protect it from all but the most unlikely meteor showers or individual hits. ${ }^{3}$ More significant factors in earth orbit are heat transfer, vacuum, particulate and ultraviolet radiation and interactions with the plasma. Assessment of these environmental effects is hampered by lack of experience with large spacecraft but is proceeding at a theoretical level. 4

I.3 Is there a way that rivals, unauthorized personnel, etc., can gain control of the SPS?

A fully operational SPS for the United States might consist of 60 satellites, a like number of rectennas, a transportation complex and a highly redundant command and communications subsystem. There is no credible way that this system could be commandeered short of war. The power beam from an individual satellite to its designated rectenna is enabled and controlled by a pilot beam. The pilot beam (which may be redundant for purposes of reliability) provides the information to the satellite to focus the power beam and to keep it precisely pointed at the rectenna. If for any reason the transmitting antenna is pointed away from the rectenna, the power beam defocuses and becomes indistinguishable from the background noise. The pilot beam is coded to operate only with its designated satellite and to preclude its duplication trom an unauthorlized sưrce.

2 "Key Crude Oil and Product Pipelines Are Vulnerable to Disruption", EMD-79-63, U.S. General Accounting Office, August 27, 1979.

3 Space and Planetary Environment Criteria Guidelines for Use in Space Vehicle Development, 1977 Revision, NASA Technical Memorandum 78119, November 1977.

${ }^{4}$ SPS Reference System Report, DOE/ER-0023, October 1978, pp. A42-A44. 
I.4 What is the basis for the claim that the satellite will have a 30 -year lifetime?

This is not a claim; rather a 30-year lifetime was selected as a design guideline for operation planning and costing exercises. The ever-lengthening lives of current unmanned satellites, however, together with the rather benign conditions in geostationary orbit (no gravity, no weather, very little wear, etc.) suggest that 30 years, with maintenance, may not be an unreasonablc goal. Refurbishment is also part of the program planning for SPS and could extend satellite lifetime considerably beyond 30 years.

I.5 Have maintenance requirements been considered in the analysis of the reference system concept? How could maintenance be performed?

Malncenance requirements have been considered in the reference system analysis as part of the reliability and lifetime analysis. Costs and manpower have been estimated; including spare parts, transportation and leve1. of effort. Much of the maintendnce associated with the rectenna would be conventional in nature, and include maintaining roads, rectenna panels and supports, the power collection and transmission systems and control center. Most of the work would entail general equipment maintenance. Estimates of labor for scheduled and unscheduled maintenance and repair of the rectenna and electric power collection system have been estimated at 64 employees 5 per rectenna.

To determine maintenance requirements for the satellite, eighteen SPS components were selected for detailed analysis. The components were selected for one of three reasons: 1) the component was representative of a class of components, 2) failure of the component results in signiticant power loss or 3 ) the component is highly stressed and could have a higi tailite rate. The nunber of personnel required for

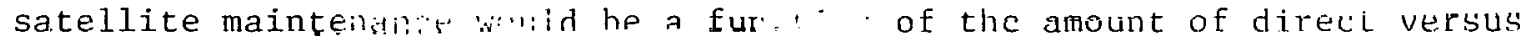
remote monitoriny. $:$ : is currently $\cdots$. .ilated that the 60-satellite system wolld be mairitained by abo.: 975 wrkers, 6 probabiy stalivici dt the GEU construction base and ferrier hack and forth to the satellites, as required.7

5 General Electric Space Division (GE) Solar Power Satelifie system Definition Study Part 4 Phase 1 Final Report, GE 1979, reported in: "Prototype Environmental Assessment of the Impacts of Siting and Construction of a Satellite Power System (SPS) Ground Receiving Station (GRS): Project Description," ERG, (November 1979).

${ }^{6}$ Briefing given on Satellite and Rectenna Construction and Maintenance, "Some JSC SPS Activities," NASA JSC, November 28, 1979.

${ }^{7}$ SPS Concept Development and Evaluation Program Reference System Report U.S. DOE/ER-0023, October 1978. 
The mission control center (MCC) would have developed a detailed listing of faulty components and spare parts would be available from the warehouse or would accompany the maintenance crew. Upon arrival, a flyover of the satellites would be made to detect non-annunciated failures. The maintenance vehicle would be loaded and defective components removed and replaced. The defective components would be returned for test and refurbishment. Each satellite would be refurbished in $3 \frac{1}{2}$ days with double shift operations. Most of the work would be performed by teleoperated machine and monitored by space workers. This high level of maintenance would enhance confidence in the projected 30 year lifetime.

I.6 Will new life support systems be required for space construction crews or is present technology sufficient?

Life support systems encompass (1) the control and revitalization of a habitable atmosphere, (2) provision of food and water, (3) solid and liquid waste management, (4) space suits and emergency equipment for personnel safety and rescue, (5) personal hygiene, and (6) instrumentation and data management equipment. While all these subsystems currently exist; additional R\&D on each of them will. be required for an operational SPS.

Basically, life support systems using techniques of regeneration will be required because the cost of providing expendable items for the life support function is prohibitively expensive. Major advances required for the SPS are likely to include oxygen recovery and closure of the water/waste management system. A significant amount of research and development has been conducted on regeneration life support processes and some tests have been performed. A continuing research program covering all the areas has been defined 8 . which could be readily adapted and extended to satisfy specific SPS requirements as these become better known.

8 Life Support, NASA Office of Aeronautics and Space Technology, Summer Workshop, Volume XI, August 1975. 


\subsection{What are the manpower and training requirements to build the}

satellite?

The number of SPS personnel in orbit would vary with the stage of deployment but would be on the order of 1000 at any given time. For example, after construction of about one-third of the 60-satellite system, one scenario would have 827 people manning the GEO base. This crew would consist of SPS construction personnel (417), satellite maintenance (383) and transportation systems maintenance (27). The SPS construction crew would be composed of four types of personnel:

$$
\begin{aligned}
& \text { 1. Base Management (17) } \\
& \text { 2. 3e3 curslruction (262) } \\
& \text { 3. Base support and operations (120). } \\
& \text { 4. Operations safety (18). }
\end{aligned}
$$

The crew would include men and women, and would be selected for sound physiological and psychological conditions well educated and highly motivated indivinuals would be selected. I0 Although laborspecific requirements have not been identified, most of the traditional occupations would be represented: electricians, plumbers, cooks, accountants, engineers, etc. Space workex training would include specific job related training as well as instruction on maintaining health, safety and well being of the space environment. A program to analyze manpower and training program requirements has been identified. This study will be undertaken in the next study phase if a decision to proceed is made.

Murh of the manpower needed to develop the SPS (including the satellites) would be those associated with traditional terrestrial projects - mining, materials extraction and processing, component manufacture, etc. In addition, construction of the satellite element would require coordinated effort at GEO and LEO staging bases, as well as support from earth bases. The space worker estimates assume 10 support people on the ground per spare worker.

9 Manpower requirements supplien by $\dot{H}$. Donald Calahan, NASA/SPS Program Manager, NASA Headquarters, Washington, D.C., December 61979.

1.0 Lewis, Bill, "Assessment of the Effects of Zero Gravity Environment on the Health and Safety of Space Workers," briefing presented at NASA Johnson Space Center, November 1979. 
I. 8 How should today's students be preparing themselves in terms of training and education so as to have a greater opportunity for more direct involvement in any future SPS undertaking?

If one assumes that SPS will become an operational system early in the next century today's students would have careers roughly paralleling the research, development, demonstration, deployment and initial operation of the SPS. Since this program involves so many disciplines scarcely anyone would be precluded from participation because of a specific career choice. However, the next ten to twenty years will of necessity emphasize research and development. This suggests that engineers will have an edge over welders, system planners will be more sought after than stock clerks, and biophysicists will more likely find SPS-related employment than nurses.

The skills mix required to accomplish SPS goals will change as the program unfolds and 30 to 40 years from now there is likely to be a strong demand for registered nurses, stock clerks and welders while many experienced SPS engineers, systems planners and biophysicists will be moving on to new projects requiring their skills.

The SPS program will require individuals at all levels of the management/organizational structure with the ability to:

- Design the SPS, including terrestrial, space and transportation elements., and components,

- Deploy the SPS; fabricate elements and construct them in epace and on parth.

- Interface with institutions, including international and local bodies, financial organizations, land owners, insurance agencies, utilities, users, etc.

- Evaluate SPS environmental and societal impacts and suggest appropriate responses.

- Operate and maintain both the space and ground components of the SPS.

While the space segment of the system may have the highest profile, visually as well as job related, the majority of jobs will continue to be in traditional fields. 
I.9 Which is the cheaper reference system design - Rockwell's or Boeing's?

Within the range of present uncertainties, total system cost is the same for both designs. While the most recent estimates show the Boeing satellite to be cheaper, it is also heavier and the transportation cost is therefore higher. Both designs assume cost improvements of a factor of 10 or more in several elements (space transportation, solar arrays, etc.) in order to make the system economically viable. Thus, their "estimates" are really more in the nature of goale. Comparable sets of figures derived in early 1979 are shown in the following table. 11

Boeing Rockwe11 (Millions of 1977 dollars)

Satellite

Ground Receiving Station

Space Transportation

Space Construction \& Support

Mass Contingency

Management and Integration

$\begin{array}{rr}3,917 & 5,328 \\ 2,242 & 3,600 \\ 3,248 & 1,872 \\ 1,463 & 1,152 \\ 1,130 & 1,872 \\ 421 & 576 \\ \$ 12,421 & \$ 14,400\end{array}$

The SPS PO is currently auditing these cost estimates. Preliminary indications are that SPS costs may be in the neighborhood of $\$ 3600$ per kilowatt, compared to the approximately $\$ 2400 / \mathrm{KW}$ estimated by the contractors. The audit is continuing, however, and will be fully reported later in the year.

The problems inherent in deriving SPS cost estimates have been treated extensively by Hazelrigg who indicates that "it is not, by any means available today, possible to predict the cost of an SPS to be builf in the year 2000, to better than about an order of magnitude."

11

Adapted from Table 3.11 of "Freliminary Cumparalive Assessinenl of the Satellite Power System and $\Lambda$ ternative Tcchnologico" by

T. Wolsko, et al, Argonne National Laboratory (in press).

12 "Costing the Satellite Power System" by Dr. George A. Hazelrigg, $\mathrm{Jr} .$, American Astronautical Society, paper for AAS 78-166, November 1978. 
I.10 Is the DOE considering alternative reference system concepts? If so, how much money is being allocated for these studies relative to the current status reference design?

The SPS Project office is evaluating alternative concepts and subsystems at the present time. For example, a laser power transmission system has been identified as an alternative to the microwave power transmission system. Solid state technologies are being investigated as alternatives to the present spacecraft transmitting antenna design. During FY79, about 15\% 13 of the NASA budget for SPS studies went into these areas. Should there be a decision to proceed with further SPS investigations after the end of a current program, the SPS PO will continue this program to evaluate emerging technologies to determine their applicability.

The present reference system is a concept being used as a "strawman" for the environmental, societal and comparative assessments. It is not an optimum concept, detailed design or recommended configuration. 14 The SPS PO has considered many other systems in the past and continues to study others as their technology develops. A partial list of alternatives considered to date would include:

ENERGY COLLECTION
o Photovoltaic
-Silicon
-Gallium Aluminum Arsenide
-Multi-Rnnd Gap
-Optimum Filter
-Cadmium Sulphide
- Thermal-Solar
- Brayton
-Rankine
-Thermionic

\section{ENERGY TRANSMISSION}

- Microwave

-Power Amplification -Amplitrons

- Magnetronons

. Klystrons

. Solid State

-Phase Control

- Retrodirective

, Ground

- Jaser.

$\overline{13,14}$ Testimony and prepared statements of Robert Frosh, NASA Administrator, and F.A. Koomanoff, Director of the SPS Project Office, before the House Science and Technology Subcommittee on Space Science and Applications, March 29, 1979. 
II. ABOUT THE COMPARATIVE ANALYSIS

II.1 Will there be a comparative analysis of the SPS with alternative energy technologies?

A comparative assessment of the SPS is part of the SPS Concept Development and Evaluation Program. The analysis sequence for the comparative assessment consists of six main steps.

o Comparative Issues Selection

- Energy Alternatives Selection

- Energy System Characteristics

o Side-by-Side Analysis of Energy Systems

- Alternative Futures Analysis

- Integration/Aggregation Technique Development

The first four steps have been taken in a preliminary assessment 15 and a methodology has been established for accomplishing all six steps. 16 The final assessment will compare the SPS and seven alternative energy technologies in the areas of cost and performance, environmental effects, human health and safety, resource utilization, and economic, societal and international issues. The alternative energy technologies to bc characterized include light water reactors, liquid metal fast breeder reaccors, advaancèed coal-f̈ired steam plants, coal gasificatior/combined cycle plants, terrestrial central station photovoltaics, and fusion reactors. In addition, an appropriate decentralized energy technology alternative wi.11. be characterized and pvaluated. The SPS Comparative assessment is scheduled for completion in June 1.980 .

15"Preliminary Comparative Assessment of the Satellite Power System, and Alternative Technologies," by T. Wolsko, et al, Argonne National Laboratory (in press).

16"Preliminary Comparative Methodology for SPS and A1ternative Technologies," Argonne National Laboratory, May 1979. 
II.2 Has a net energy analysis been done which compares the SPS with alternative energy technologies?

Energy analyses of the SPS have been compared by the Johnson Space Center, 17 the Marshall Space Flight Center, 18 the Energy Research and Development Administration Task Group on Satellite Power Stations, 19,20 the Jet Propulsion Laboratory, 21 the SPS Project Offic 23,24 and the University of Illinois Center for Advanced Computation. 23,24 SPS energy ratios have been found that range from marginally favorable to very favorable in relation to other energy technologies.

Considerable controversy' exists regarding energy analysis methodologies and their results. A particular point in dispute is whether or not fuel should he included in the system boundaries. Perhaps the most common measure used in energy analysis is the net energy

17 Initial Technical, Environmental and Economic Evaluation of Space Solar Power Concepts, JSC 11443 Volume I, National Aeronautics and Space Administration, July 15, 1976.

18 Satellite Power System, NASA TM X-73344,' National Aeronautics and Space Administration, November 1976.

${ }^{19}$ C. Bloomquist, A Survey of Satellite Power Stations, PRC R-1844. PRC Systems Sciences Co., Los Angeles, California, September 1976.

${ }^{20}$ Final Report of the ERDA Task Group on Satellite Power Stations, ERnA-76/148, Fnergy Research and Development Administration, November 1976 .

${ }^{21}$ Livingston, Floyd R:, et al, Satellite Power'System (SPS) Preliminary Resource Assessment, 900-805, Rev. A, Jet Propulsion Laboratory, California Institute of Technology, Pasadena, California. August 7, 1978.

22

Kotin; A., SPS Preliminary Societal Assessment: Resources Requirements (Critical Materials, Energy and Land), DOE HCP/R-4024-02, October 1978, pp 66-70.

23

R. Herendeen, T. Kary, J. Rebitzer, Energy Analysis of the Solar Power Satellile, ERG Dü. No. 265, Energy Rcscarch Croup, University of Illinois at Urbana, Champaign, Urbana, IL, Novemher 1978. 24

4 Herendeen, R.A., T. Kary and J. Rebitzer, "Energy Analysis of the Solar Power Satellite," Science, 3 August 1979, Volume 105, Number 4405, pp 451-454. 
ratio defined as

electrical energy out over lifetime

primary, non-renewable energy in over lifetime

For many purposes it is desirable to exclude fuel from the denominator of this expression. Doing so for SPS and other solar energy systems that use no primary, non-renewable energy as fuel excludes their most desirable feature. Solar photovoltaic systems also tend to have lower energy ratios than fosail or luclear systems because of the current high energy intensities involved in the production of solar cells. However, when fuel is included in the calculation the energy ration of nucleas aul fossil systens drop to a fraction of the lowest value found for SPS in the studies cited above.

As a subtask of the Comparative. Assessment, a net energy analysis is being conducted which will attempt to resolve some of the controversy inherent in this topic by carefully comparing the two solar cell optlons of the SPS (silicon and gallium-aluminum-arsenide) with coal, nuclear and terrestrial solar electric energy systems. The final comparative assessment report is scheduled for completion in June 1980.

II.3 How much disxuption of human settlement patterns and wildlands will the SPS rectenna system create in comparison to coal and oil shale fuel cycles?

A detailed study is in progress at Rice University to find arcas in the United States that satisfy specifled criteria such as minimum pupulativin densicy, non-agricultural use, water availability, noninterference with flyways of migratory fowl, ctc. ${ }^{5}$ Tlie sludy w111 reveal areas that are potentially suitable for rectenna siting, or as sites for other power plants, as a functiun of input criteria. Determination of ultimate suitability would require site-specific analyses for competing scenarios which would include estimates of disruption to human sețtiement. piatentus and widlands.

\footnotetext{
${ }^{25}$ The final report is due in May 1980; preliminary results were given in: Blackburn, James B. Jr, and Bill A. Bavinger, SPS Preliminary Societal Assessment: Mapping of Exclusion Areas for Rectenna Sites, DOE HCP/R-4024-10, October 1978.
} 


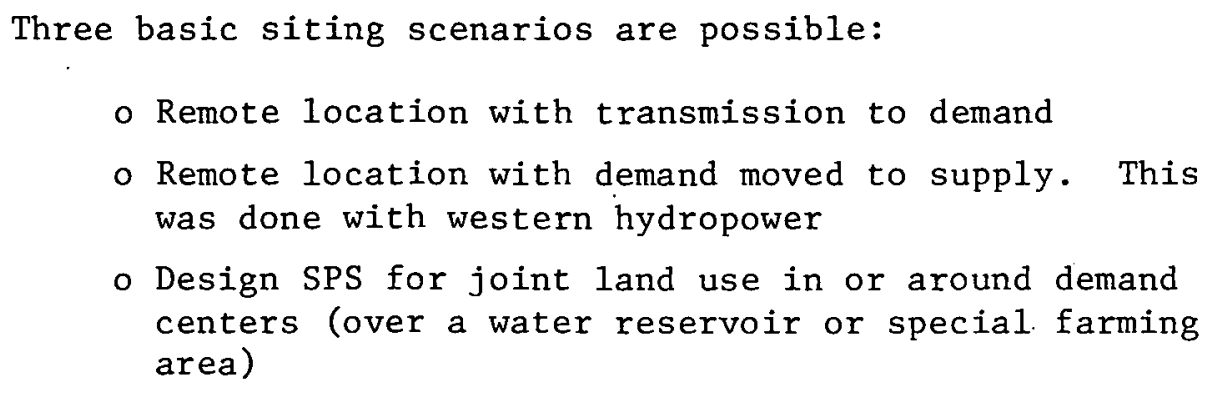

How human settlement patterns change depends on the location of SPS rectenna sites in relation to year 2000-2030 population and industry centers and each scenario would create different effects.

The SPS Comparative Assessment is examining the land requirements of SPS and alternative technologies and will provide information to more fully answer this question. The final comparative assessment report is due in June 1980 .

II.4 Would the SPS be functional soon enough to obviate massive coal and oil shale exploitation or do the timeframes for utilization of these alternative technologies and attendant environmental impacts overlap?

U.S. energy consumption is expected to increase at a small, but significant rate in the midterm (1985-1995). A recent DOE Energy Information Administration study 26 projected energy consumption to increase at annual rates between $2.8 \%$ and $1.6 \%$ for the midterm period. Although this is lower than historic trends (the annual race of 1ncrease fur Llie 'G2-'72 pesiul was J.0\%), by 1295 it will result in annual energy consumption, respectively, $165 \%$ or $135 \%$ greater than 1977 consumption of 80 quadrillion Btu. Continued reliance on fossil fuels will accompany this increase at least through the short and mid terms. The level of development and utilization of coal and other fossil fuel sources during the next 20 to 30 years will depend on the actual increase in demand for electricity and the degree to which conservation options are utilized by society. The SPS holds promise only for the long term, and could not make a significant contribution to electric supply for the next 25 years.

26

Energy Supply and Demand in the Mid-Term: 1985, 1.990 and 1995, DOE/EIA-0102/52 Order No. 476. April 1979. 
II.5 Would a breakthrough on fusion obviate the need for SPS? What forms and amounts of energy would fusion energy replace that would reduce the need for SPS?

Fusion is a baseload central station electrical option, and therefore a companion technology to SPS. A competitive scenario exists only if both options are available at the same time, at similar costs, and under conditions for which energy supply shortfalls can be satisfied without having to resort to a mix of both options. If both are technically and environmentally acceptable, then other criteria would determine if SPS would be part of the energy portfolio aloing will fuslun. A breakthrough in fusion would call for a reevaluation of all immediate post-2000 electric technologies.

IT.6 Wouldn't a breakthrough in terrestrial solar technologies reduce or eliminate the need for sPs? In particular, wouldn't advances in photovoltaics benefit terrestrial applications to the point where the SPS would be obsolete or comparatively uneconomical?

If we compare baseload terrestrial photovoltaics to SPS, then a breakthrough in solar cell technology would bring down the cost of both systems. Most likely the decrease would favor terrestrial photovoltaics, but storage cost must. also be reduced to increase the competitive position of baseload applications of terrestrial phrtovoltaice. Thercforc, a breakthrougl ill plutuvoltalc technólogy and/or storage technology would require careful analysis against supply/demand, and economic, societal and environmental issues at. that time.

II.7 What impact will development of the SPS have on the labor market compared to alternate energy endeavors. - Will it be labor-intensive or capital-intensive?

A quantitative answer is not available at this time. However, it is known that SPS, as well as terrestrial photovoltaics and other distributed solar technolgies, will most likely utilize mass production facilities, most of which will be automated. Although the space construction portion of the satellite and operationn will be highly automated, support service, rectenna construction, and maintenance labor requirements will be high and comparable to coal, nuclear, and central station solar technologies. The distributed technologies will differ in that they will utilize more local labor to assemble (roof-top mndification, etc.) install, operate and maintain these technologies than does SPS or conventional technologies. The SPS Comparative Assessment, scheduled for completion:n June 1980, will more fully address this question. 
III.1 A prominent concern is the microwave bio-effects of the SPS power transmission system. What happens to people and ecosystems outside the rectenna site should control of beam directionality be lost?

Microwave power densities have been calculated-for the case of total failure of the phase control system.27 If the uplink pilot beam transmitter at the rectenna is shut off, for example, the sub-arrays on the satellite antenna will no longer be phased together and the total beam will be defocused. The peak intensity of the beam at ground level drops to $0.003 \mathrm{~mW} / \mathrm{cm}^{2}$ and the beam width greatly increases. The power density of a defocused beam is less than the ambient level for television transmissions within the average city and is significantly less than the U.S. and the U.S.S.R. guidelines (10 and $0.01 \mathrm{~mW} / \mathrm{cm}^{2}$ respectively). Under normal operations, the general population and off-site ecosystems would be exposed to power densities ranging from 100 to 100,000 times below the U.S. standard limit (up to 100 times below the U.S.S.R. standard limit). Preliminary investigations in several priority areas (e.g., immunology and hematology, mutagenesis, carcinogenesis, reproduction, teratology and growth) reveal no expectation of impairment of the general population or animal and avian members of ecosystems outside the rectenna site. 28 Further investigations are planned in these and other areas. For example, a very extensive experiment to study the effect of low-level microwave radiation on the European honey bee has been conducted at the University of California at Davis. The results are now under analysis and a report is expected in the near future.

Should a second pilot beam be set up (e.g., by terrorists) to re-direct the beam, the beam will also defocus. This is a failsafe feature of the phasing system. In addition, the rectenna design includes sensors to detect any large changes to incldent power density; this information would immediately be transmitted to the antenna to cease operations. 27

III.2. What are the atmospheric heating offects of decentralized solar energy systems compared to the SPS?

All of the waste heat generated by decentralized solar energy systems on earth would be dissipated in the atmosphere near the earth's surface. The amount of waste heat would depend upon the size and design features of individual systems. Undesirable effects produced by this waste heat would depend upon the characteristics of the environmental surroundings.

27 Technical information on the microwave power transmission system is taken from the SPS Reference System Report, \#DOE/ER-0023, October 1978, pp. 30,33, 45

${ }^{28}$ Briefing hy John Allis of EPA on SPS Microwave Bioeffects Studies, presented at a June 1979 SPS Review in Washington, D. C. 
Most of the waste heat generated by SPS would be dissipated in space. Nevertheless, about 7 percent of the energy delivered to an SPS rectenna site would be lost as heat in the atmosphere near the earth's surface. This heat loss is about the same as produced by contemporary suburban developments near large cities. Localized effects produced by SPS waste heat near rectenna sites, if they were to occur, would depend upon the characteristics of the environmental surroundings, as is the case for decentralized solar systems.

The waste heat which would be produced near SPS rectenna sites is not expected to affect regional weather patterns. Large terrestrial power generating systems capable nf producing euergy capacities equivalent to SPS would be expected to produce regional and global weather and climate effects which would be greater than any currently envicioncd froili 3PS.

III. 3 will the SPS damage the ozone layer and create a "greenhouse" effect by heating up the atmosphere?

The bulk of the ozone is contained in the stratosphere between about 10 and $40 \mathrm{~km}$. This region has been under intengive investigation during the past ten years. Preliminary analyses ${ }^{30}$ indicate that effluents from SPS rocket launches would have a negligible effect on the ozone in this region. Above about $50 \mathrm{~km}$., where the ozone concentration is less than $1 \%$ its peak value in the stratosphere, preliminary analysis suggests that ambient water concentrations, especially above $70 \mathrm{~km}$, may be appreciably enhanced and may become involved in the complex chemical mechanisms which control ozone concentration at these altitudes. Even the direction of these effects is not predictable without a much closer examination. However, the above-mentioned preliminary calculativis lidicate that the globally averaged change in total ozone would be negligible (i.e., nnt deteclable) and that, consequently, the change in intensity of ultraviolet radiation at the ground surface would also be negligible.

The reduced abillty of the atmosphere to transmit long wavelength (infrared) radiation relative to ohorter wifulungth (visible and uitraviolet) radiation, commonly known as the "greenhouse" effect, most directly arises through the addition of light rcflectilly aerosols and infrared absorbing molecules $\left(\mathrm{CO}_{2}\right.$ and $\left.\mathrm{H}_{2} \mathrm{O}\right)$. As noted in the iulevane docuiments 31,32 , the relative abundance of these substances in the lower atmosphere is so large that SPS contributions are considered to be completely negligible. The water vapor budget in the stratosphere and above is poor1y understood, so that at altitudes above 70 or $80 \mathrm{~km}$., SPS water vapor

${ }^{29}$ SPS Preliminary Environmental Assessment, DOE/ER-0021/2, October 1978, pp. 86, 106.

${ }^{30}$ SPS Preliminary Environmental Assessment, DOE/ER-0021/2, October 1978, pp. 86-91. 
releases may enchance cloud cover. Although considerable uncertainty exists as to climatic effects arising from SPS-related perturbations in stratospheric and mesospheric composition, such perturbations are not expected to be highly significant. 31

III.4 Why have only two years been allotted for atmospheric impact studies?

No fixed time has been "allotted" to any of the SPS assessment activities. Current atmospheric impact studies are part of the Concept Development and Evaluation Program, which for administrative reasons is limited to three years. The planned studies in that time frame are to identify potential impacts on the atmosphere and to determine what is known and unknown about each impact. If, after considering all results of CDEP, it is decided to proceed further, the potential atmospheric impacts identified in CDEP will be addressed in greater depth and will continue until uncertainty regarding them has been reduced to a reasonable level.

III.5 Will communication systems already in place be disrupted by SPS operations?

Communications and other electromagnetic radiating systems must be designed and operated according to national and international rules and regulations for radio spectrum use. The SPS would have to satisfy thcse rules and regulations for compatible spectrum use, and where necessary, develop mitigating strategies to account for otherwise avoidable interference situations. Mitigating strategies can be (1) designed into new equipment, (2) followed in operating new equipment, or (3) applied to existing equipment with the users' agreement.

Microwave energy from SPS could interface with the operation of communication and other electronic systems now in use. In the absence of mitigating strategies, SPS interference effects would most likely occur in space and within about 100 kilometers of rectenna sites.

Effects on satellites in space can be prevented by appropriate design of the SPS microwave transmission system, by coordinated operations with other satellites, and by including filters and shielding in future satellite designs.

Maximizing the distance between rectenna sites and taking advantage of the shielding provided by terrain features are two mitigating stategeies which could be used on earth. Interference effects which cannot be avoided by these cechnlyues

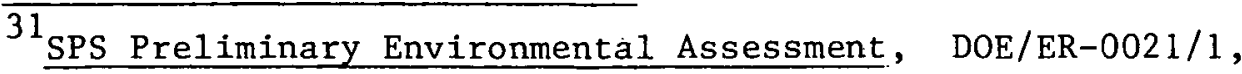
October 1978, p. 32 .

${ }^{32}$ SPS Preliminary Environmental Assessment, DOE/ER-0021/2, October 1978. 
can be prevented by including conventional filters and shielding in new equipment designs and retrofitting existing equipment by mutual agreement. At this time, no unavoidable interference problems due to SPS are evident.

III.6 Would the current SPS reference system design create significant additional conflict over utilization of the geostationary orbit?

Obtaining orbital slots and radiofrequency allocation for many tens of SPS satellites - or other satellites - would require extensive international discussion and àgreement. Use of the geostationary orbit by telecomminications and other geosynchronous satellites has been increasing, and along with it, competition for orbital position. To date, the International Tclecommunications Union, I.T.U., has assigned orbital slots on a first come, first served basis. However, this approach has created increasing conflict in the international community which considers the resource open to common use, and not subject to national appropriation. Conflict focuses on issues of exclusive use, technical. debate over the number of orbital positions, and political disagreement on the Bogota Declaration, in which eight equatorial nations claim sovereignty over the geosynchronous urbit above their borders. 33 During the SPS operational timeframe it is anticipated that multiple use communications platforms will exist for which multiple communications antenna systems would be co-located. Such an arrangement may greatly reduce the slot allocation problem.

In addition, the level of microwave energy generatod by and radiated from the SPS spacecraft has the potential. to cause interfercnce with communication or other satellites (including SPS's) located nearby. It is anticipated that multiple use conumications platforms will come into being early in the next century which would tend to reduce the slot al lucarion problem. The SPS has focused attention on this issue which must be resolved whether or not SPS goes forward; an operational SPS, however, could be expected to intensify the debate.

${ }^{33}$ Christol, Carl Q. SPS Preliminary Societal Assessment: International Agreements. DOE HCP/R-4024-08, October, 1978. 
III.7 How will SPS's in GEO affect the aesthetics of the night sky?

SPS spacecraft would, if built according to the current Reference System design, be visible on clear nights. The visible light from each spacecraft (sunlight diffusely reflected from the solar blanket array) would produce about 1/1000 the light of a full moon; the satellites would be brighter than any object in the night sky except the moon. 34 They would be brightest near midnight, comparable to Venus, and would become invisible near dawn or sunset since the large solar arrays would be seen "on edge" at these times. 35

If 60 SPSs were positioned uniformly in GEO over the continental United States, the appearance would be that of a chain of bright planetlike objects extending (as viewed from the U.S.) in a nearly straight line from east to west across much of the southern sky. They would be separated slightly less than are the stars in Orion's Belt. These bright objects would be in fixed position relative to the earth, and stars and planets would thus appear to move from east to west past them. The relative brightness of the satellites, and their.consistent spacing would contrast with the random configurations of stars that form the traditional constellations. In addition, use of 7-power binoculars would clearly show them to be rectangular structures rather than points of light. Light from a large number of SPS satellites would brighten the night sky due to atmospheric scattering, and would be of some concern to astronomers.

At intervals of six months, the satellites would pass through the earth's shadow at approximately midnight for a number of days in succession: an occurrence something like a lunar eclipse. Satellites would gim and redden on encountering the edges of the shadow, darken, then reappear about 10 minutes later. 'The earll's shadow could he. seen to progress from east to west along the line of satellites.

The current Reference System design calls for use of highly refiective material for the satellite transmitting antenna. Specular reflections from the large flat areas of the transmitting antenna would periodically direct bright beams of light across the night side of earth. The reflection would be comparable to the full moon for two

${ }^{34}$ SPS Preliminary Environmental Assessment, DOE/ER-0021/2, October 1978 .

35 Livingston, L.E., Briefing on Visibility of SPS, presented at NASA JSC, June 6, 1979. 
nights in spring and summer, lasting about 2 minutes. ${ }^{36}$ The Environmental Assessment indicates that this amount of concentrated light from a small object may pose an eye damage risk to someone viewing the satellite through a telescope. Therefore, the present design for a highly polished antenna surface will be changed to eliminate the risk by permitting only diffused reflection of light. Means to further reduce the intensity of reflected light are also under consideration.

III.8 Have psychological factors affecting manned operations in the space environment heen taken into account in studies of the health and safety of the space workers?

A prelimlnary study of the psychological factors affecting SPS space workers is in progress. Existing data that addresses this problem are available from the Skylab astronauts and Russian cosmonauts, submarine crews, oil platform workers, and the construction personnel on the Alaska pipeline. The results of the study are anticipated in March 1980; the question is of paramount interest and will be pursued throughout the SPS program.

IV. ABOUT THE SOCIETAL EFFECTS

IV. 1 Why do we need centralized (baseload) power and a national energy gird? Wouldn't a centralized system like the SPS reinforce the control that large institutions exert over people's lives? Wouldn't reliance on the SPS inhibit a widely expressed desire to be more self-reliant through control of one's own energy supply?

The electric utility industry began as a highly decentralized activity with generation 1 nrated clooc to the cunsufiner and with virtually no interties between systems. Advancing technologies and economies of scale led to mergers and interconnections and have permitted utilities to build larger plants and larger rapacity trans micoion lines at decreasing unit costs. Interconnections have improved the reliability of utility systomo und reduced generating reserve requirements. Presently, there are three major transmission networks one each in the East, West and Texao - composed of utilities and pools intertied with each other, but the three networks are not connected. There is no national grid system, although its desirability continues to be debated.

36 Iivingston, L.E., "V1sibility of Solar Power Satellites from the Earth", NASA Johnson Space Center, JSC-14715 report, Feb., 1979. 
The SPS is a centralized (baseload) power concept because it would transmit an essentially constant output through a grid network from a site located at some distance from the point of end use. It is one of several baseload concepts proposed for use in the post2000 era, and like the other systems would work best in a fairly substantial power pool. The SPS does not require a national grid, however.

The debate over centralized vs. decentralized energy systems has arisen as one consequence of the tail-off of scale economies in the utility industry. Even assuming that utilization of decentralized energy systems increases over time, this does not rule out the need for a centralized system to provide massive amounts of power for energy intensive processes (the production of aluminum and silicon used in decentralized technologies, for example) and to serve customers who do not find decentralization feasible. In this regard, the Argonne National Laboratory has recently published a report 37 . which suggests that it is the small commercial and industrial enterprise that would most likely suffer in a decentralized scenario.

Also, most decentralized technologies rely on a central system to provide back-up energy. If this adds to the existing peak demand, more centralized generating capacity would be needed, the utilities' load factor would be worse and electricity costs would be higher. On the other hand, if decentralized users could coordinate their demands to coincide with off-peak hours this would reduce total generating capacity required, improve the utilities' load factor and reduce the cost of electricity. It should thus be possible for distributed and centralized energy systems to develop a symbiotic relationship. Greater individual self-reliance through end-user ownership of decentralized systems, need not be threatened by the cu-existence of contralized systems. 38

37 Asbury, J.A. and S.B. Webb, "Centralizating or Decentralizing? The Impact of Decentralized Electric Generation," ANL/SPG-16, Argonne Nationa1 Laboratory, March 1979.

38"Centralized vs. Decentralized Energy Systems: Diverging or Parallel Roads?", prepared for the Subcommittee on Energy and Power, House Committee on Interstate and Foreign Commerce, by the Congressional Research Service, May 1979, p. 18. 
IV.2 How could SPS development lead to decentralization of social institutions and decision-making structures?

The DOE assessment of the SPS has not formally dealt with this question, so that this answer must be speculative in nature. This question and the preceding one presume that decentralized energy systems lead to decentralization of social institutions and decisionmaking. Frankel 39 and Stiefe 140 suggest that this may not necessarily be the case. Both see the possibility that distributed solar energy technologies could be mass-produced, by huge factories and distributed to consumers by national (or international) merchandisers. Stiefel suggests that Jarge corporations are ideally suited for mass-producing and distributing the many units needed for derentralized oyotems. This sicuarion wnuld ongender some degree of individual ownership and control, but produce no fundamental change in the institutional or economic structure of society.

There are a number of ways by which SPS development could encourage decentralization:

- photovoltaics research could lead to more cost-effect groundbased systems for end-use applications

- mining, refining and manufacture of photovoltaic materials and other system components will have some, as yet undetermined, impact on employment and population growth in rural areas; the result could be some shift in the balance of economic power between rural and urban areas and geographic regions of the country

- SPS development could contribute to overall stability in energy supply and prices, relieve long-term inflationary pressures and give individuals more confidence in making decisions about the future (ergo decreased sense of "being powerless")

Ir does not follow that because sPS development will require a high degree of central direction, decentralizing trends will be thwarted. Janowitz, in his book The Last Half-Century: Societal Change and Politics in America, discusses the War on Poverty and concludes that strong central planning is essential for genuine decentralization. Consider,

\footnotetext{
${ }^{39}$ Frankel, "Some Thoughts on Solar Energy and the Decentralist Vision", Office of Policy Evaluation, U.S. Department of Energy, 1979.

${ }^{40}$ Technology Review, October 1979, pp. 56-66.
} 
for example, that the success of decentralized energy technologies in the marketplace will depend in large part on the central direction of the federal government.

The SPS would produce centrally generated electricity at sites remote from the end-user, but it could still contribute directly to decentralization if its development were to create a dispersed system of ownership. Such a possibility is found in Vajk's taxpayer stock corporation model. 41 This financing scheme would diffuse ownership among the general population through the apportionment of shares in a so-called U.S. Powersat Service, based on the fraction of an individual's taxes devoted to the corporation. However, since Vajk says there is no historical basis for evaluating the scheme, it may be more realistic to assume some other financing scheme (which could employ this concept as one of its components) would be used. In this case, decentralization through SPS development is more likely to occur by indirect means.

IV.3 What are the opportunity costs of developing the SPS? Won't the diversion of so much capital rob other promising energy technologies of development funds and leave the nation less flexible in responding to energy needs? What does the country do for its energy while it waits for the SPS to come on line?

In preliminary program phases, SPS incurs essentially no opportunity costs, since it does not reduce the development potential or funding of other promising technologies. SPS funding in fiscal 1979 was $\$ 6.6$ million; this accounted for less than $2 \%$ of the projected DUE budger fur. sulair regearch and development studies, ${ }^{42}$ and is less than $0.1 \%$ of the total energy research and development budget.

A decision to fully deploy a Satellite Power System would be accompanied by a massive financing effort and a decision to obtain the rcsultant power in this manner rather than in some other way. Opportunity costs would therefore be incurred. It would not, however, necessarily restrict research funds or inhibit the early development of other promising energy technologies. Demand for electricity will grow significantly by 2000 , and neither the SPS nor any other single energy technology will be able to supply all electric demand. It is likely that many systems will be developed to provide maximum flextbllily in responding to energy needs.

${ }^{41}$ Vajk, et al, SPS Preliminary Societal Assessment: Financial/ Management Scenarios, DOE 非HCP/R-4024-03, October 1978.

42 Report of the Comptroller General of the United States. "The Magnitude of the Federal Solar Energy Program and the Effects of Different Levels of Funding." GAO:EMD-78-27, February 1978. 
The resulting mix, and hence the exact opportunity costs, will be decided in a rather dynamic fashion over time by economic and political factors that can scarcely be foreseen now.

The SPS would come on line gradually (10 GW per year are currently envisaged) and would generally meet increasing demands or replace obsolete generating capacity.

IV.4 Who will be the economic beneficiaries of the SPS? The impression is that only aerospace 'companies and their workers will benefit.

The aerospace industry may be the most visible group to benefit from the SPS. Other sectors, although less visible, would significantly benefit, the. EPS would nut be developed by the aerospace industry alone.

All industries involved in the SPS, and their employees would benefit from the SPS. Affected Industries include chemicals and allied products, mining, primary metals, semi-conductors, space vehicle manufacture, ground operations and supporting services. Of the large amount of solid material required for an SPS system, over 90 percent is in the ground based rectenna and approximately 6 percent is in the launch site complexes. Only 2.4 percent is in the SPS satellites, and space transportation system. Of the labor required to build, operate and maintain and repair the SPS system, more than 99 percent can be classified as belonging to convenliullal occupations and industries $\frac{1 j}{4}$ sted above, and less than 1 percent work in the space environment. 4,44 other industries to directly benefit would include those who own land to be used for rectenna and launch sites, finance and manage an SPS, and distribute SPS power (utilities).

Communities and individuals would benefit indireetly, througlı an economic multiplier effect that accompanies any economic development. Each individual directly benefitting would, in turn, distribute benefits to others directly. Significantly, all power users would benefit if the SPS can provide cheap, reliable electric power. In

43"Satellite Power System (SPS) Environmental Impacts-Preliminary Assessment," NAS $/$ JPT, April 1, 1978.

44"Satellite Power System (SPS) Preliminary Resources Assessment," Jet Propulsion Laboratory-California Institute of Technology, JPL, August 7, 1978. 
particular, a recent study reported that the SPS, a central solar technology, might more reliably serve the energy needs of the aged than would decentralized solar technologies. 45 Perhaps the least visible sector would be the future beneficiaries of space utilization that SPS capabilities would make possible.

IV.5 Who will provide insurance for the SPS? For damage from occupational exposure, wandering beams and crashes à la Sky Lab?

A market for space insurance has been developing in the U.S. and England since launch of the first commercial satellites, in the ' 60 's. 46 As with other industries, the space industry has sought to protect itself from loss of investment; a space insurance market has developed that includes coverage for loss against R\&D, manufacture, launch and operation of satelljte systems.

However, it appears that a satellite system with the scope of the SPS would challenge the existing space insurance industry. The SPS Project office has therefore contracted a major space insurance broker to determine how the industry would respond to the SPS. The study is to (1) review the history of space insurance coverage; (2) identify SPS insurance risks by component (satellite, microwave power transmission system, etc.) and program phase (construction, operation, etc.); (3) identify the insurance industry response to the SPS; and (4) determine risks the insurance industry could indemnify and estimate the cost of coverage.

The nation that develops an SPS would be liable, legally, for any damage that might occur, and wonld require private developers to insure the system. The 1972 multilateral Convention on International Liability for Damage Caused by Space Objects holds the launching state "1iable to pay compensation for damage caused by its space object on the surface of the earth or to aircraft in flight." Were an international SPS developed, the states involved would be held jointly liable.

${ }^{45}$ Cambe1, Ali, G.A. Heffernan. Implications of an Aging Society on Satellite Power System. The Office of Energy Programs, School of Engineering and Applied Sciences, The George Washington University, December 1979.

${ }^{46}$ Barrett, James and Smith, Delbert, "The Role of Insurance in Expanding International Space Opportunity," paper presented at the Thirtieth International Astronautical Federation, Munich, Germany, September 1979. 
Note: The pilot uplink beam controlling the microwave transmission would preclude the possibility of "wandering beams. Objects placed in geostationary orbit (such as SPS) where there is no atmospheric drag, can rather easily be maintained there indefinitely. Skylab could have been maintained in orbit as well; for a variety of reasons, none involving technological capability, it was not.

IV.6 Why is it necessary to study the military implications of the SPS? Is the SPS's primary purpose a military one? How vulnerable is the system to sabotage and therefore to disruption in the supply of energy?

The SPS is an energy system. It may have military applications; several have already been suggested. 47 However, to be a viable energy system the SPS should be kept. out of the military realm.

Preliminary assessments of the military implications of the SPS were.made by Bain ${ }^{40}$ and Ozerof ${ }^{49}$. The objectives of the investigations were (1) to identify the potential military uses for the SPS and how these would affect international relations, and (2) to identify the relative vulnerability of the SYS to overt military action, terrorist attacks and sabotage. The SPS Project Office accepted the findings of these preliminary assessments, and the general consensus among other investigators who touched on the subject, that: (1) a completely internationalized SPS would have the most beneficial effect on international relations. (indeed, on domestic acceptance of the system, as well) and, (2) any military application would be likely to destabilize international relations.

Internationalization of the SPS could nearly eliminate the vulnerabili.ty of the system to overt military action, especially if participation in its development were broadly-based and substantial. 'l'he system might still be vulnerable to terrorist attack or sabotage although, as Bain and ozeroff found, it is unlikely that the space segment would be threatened by such actions. The rectenna facility would be no more vulnerable to these actiono than other large industrial

${ }^{47}$ See, for example, Berger, Howard, et al, "Effects of Technological Advances on International Stability: High Energy Lasers in Space," Science Applications, Tnc., August 1977.

48 Bain, Claud N., SPS Preliminary Societal Assessment: Military Implications, DOE HCP/R-4024-11, October 1978.

${ }^{49}$ Ozeroff, Michael J., SPS Preliminary Societal Assessment: Military Implications, DOE HCP/R-4024-01, October 1978. 
complexes or power plants, and might, in fact, be les $\$_{0}$ vulnerable since no terrestrial fuel supply lines are required.

A follow-on study has been initiated to improve upon the preliminary assessment. Its purpose is to make an in-depth analysis of the ways to counteract real and perceived potential military threats and vulnerabilities of the SPS and its components. This study will be completed in May 1980.

IV.7 Will development of the SPS seriously deplete any of the earth's resources?

Two independent studies have been completed which address the question. 51,52 In both cases the answer is "no." Both studies screened the twenty two basic materials required for SPS production and both found some problems in the supply or production of certain materials.

The more serious problems are those associated with the solar cell materials (gallium, gallium arsenide, sapphire, and solar grade silicon), and the graphite fiber required for the satellite structure and space construction facilities. In addition to these mercury, tungsten and silver were found by both investigators to be potential problems as were kapton, borosilicate glass and liquid hydrogen.

Most of these are problems in terms of currently identified reserves, production capabilities, import requirements and the like and could be ameliorated. For example, gallium, which both investigators class as perhaps the nost serious problem is judged "not to be a limiting factor over the long term" by the Aluminum Company of America."

50 "Key Crude $0 i 1$ and Product Pipelines are Vulnerable to Disruption," EMD-79-63, U.S. General Accounting Office, August 27, 1979.

$51_{\text {Kotin, Alan, SPS Preliminary Societal Assessment: Resources }}$ Requirements, DOE HCP/R-4024-02, October 1978.

52 Teeter; R.R. and W.M. Jamieson, "Preliminary Materials Assessment for the Satellite Power System," Battelle Columbus Laboratories, September 1979.

53 "Survey of Availability and Economical Extractability of Gallium from Earth Resources," Aluminum Company of America, October 19.76. 
IV.8 Have other countries been approached to participate in SPS studies? If so, which ones?

No formal arrangements have been made between the U.S. and foreign countries or international agencies to participate in studies sponsored by the SPS Project office. Informal contacts have been made with the European Space Agency and several individual countries in Europe and throughout the world. Interest in the SPS concept is widespread and growing among members of the international scientific community. Individuals from Czerhnslovakia, England, France, Genulny, Japan and Russia have published the results of recent, independent work on various aspects of satellite power systems $54^{\prime}$ and the European Space Agency has 'prepared a survey report on the subject. 55

Obviously, if the SPS is to be internationalized, formal arrangements with other nations and international agencies will have to be made. As part of the current assessment program, a study is being prepared to develop options for involving the international community in any future SPS program activities.

IV.9 Who would provide SPS development funds and who would control and maintain the SPS once it was developed?

This is as yet an open question. Several financing and management options have been identified which could support development of the SPS 56,57 The form of the organization has yet to be worked out, although there is likely to be a wide range of participante, both rational and international, publ, c and private. The general consensus among the principal investigators involved in the preliminary phases of the SPS is that international cooperation in $R \& D$ and some commersialm lzation would be highly desirable. The International Telecommunications

54

See for example the "Abstrart nf Papers," XXXth Internationd. Astrunaut1cal Congress of the International Astronautical Federation (I.A.F.), September 16-22, 1979, Munich, Federal Republic of Germany.

55 Ruth, J. and W. Westphal, "Study on European Aspects of Solar Power Satellites," European Spáce Agency, June 1979.

${ }^{56}$ Kierulff, Herbert E., SPS Preliminary Societal Assessment: Finanidil/Management Scenarios, DOE HCF $/$-4024-13, October 1978. .

57 Vajk, J. Peter, SPS Preliminary Societal Assessment: Financial/ Management S.cenarios, DOE HCP/R-4024-03, October 1978. 
Satellite Organization (INTELSAT) is an example of an existing international framework that an SPS organization might be modeled after.

Kierulff. showed that it would be extremely difficult for the private marketplace to completely finance an SPS. Thus, the federal government would have to provide a major portion of the funding and/or guarantee investment vehicles in the late 1990's and early $2000^{\prime}$ 's as was done in the early phases of nuclear power and communications satellite development.

Control of the system would rest to a large extent with the investors and whatever organization they established after approval of all concerned parties. The federal government would also exercise control through regulation. State and local governments would exercise a degree of regulatory control over siting and operation of the rectenna facilities. However, as Kotin noted 58 , some of the key regulatory issues which remain to be resolved involve jurisdictional conflicts between the various levels of government and conflicting siting and land use policies.

At the international level, certain control mechanisms already exist for satellites operating in geostationary orbit. The International Telecommunications Union assigns portions of the radiofrequency spectrum to the various users and regulates signal interference characteristics of satellite systems. The organization which develops and maintains the SPS will have to abide by other existing international space treaties and will, itself, almost certainly be the cause of several new international treaties and regulatory bodies.

IV.10 Is a disruption of SPS power likely? What happens to an area which derives some or all of lits entergy from an SPS shonld such an event occur?

The SPS is envisioned as a large base load power system connected to a power grid. It will be handled like any other power source on the grid. As a contingency against loss of power, utilities are required to maintain a portion of their total generating capacity on line as "spinning reserve". In the event that a unit(s) experience sudden failure (loss of power) these spinning reserve units instanteously cut in to provide power to the grid. Transmission line interties to other utilities and pools are also traditionally used to provide immediate power flow into the grid.

A preliminary investigation of the SPS by some electrical engineering experts has foutul that the SPS may he more reliable than existing power generating systems (nuclear, coal, oil, gas turbine, etc.). ${ }^{9} \mathrm{SPS}$ would be

${ }^{58}$ Kotin, A. SPS Societal Assessment: State and Local Regulations as Applied to Microwave Rectenna Facilities, DOE HCP/R-4024-05, October 1978, pp 44-46.

${ }^{59}$ General Electric Presentation at NASA/Johnson Space Center, August 16, 1979. 
generating power a higher portion of the time and would be less prone to non-scheduled power outage. However, interruption of SPS power will occur at known periods of time due to shadowing of the satellite by the earth. Fortunately, these outages occur at local midnight when power requirements are low. A 5 GW SPS unit would be connected to a pool60 30-35 GW or larger, and the scheduled SPS outage would be accommodated by reserve within the pool, or through interties.

No area would derive all of its electrical power from the SPS. A 5 GW SPS unit would not be used to supply more than about $20 \%$ of the total electric generation capacity for any single utility or pool. Nonscheduled disruption of SPS power would be highly unlikely, but not impussible. Were partial or complete outage of an SPS unit to occur, power levels would be maintained by one or a combination of the mechanisms outlined above.

IV.11 Is there any public awareness of the SPS as a major candidate for long term energy generation?

There 1s some public awareness of the SPS as a long-range energy option, but no systematic attempt has been made by the Project office to assess its extent. It can be inferred that knowledge of the SPS is growing. For example, the Project office distributes approximately 3,000 copies of each report it publishes. These reports are distributed to a wide national and international audience that includes universities, government agencies, libraries, public and private interest groupc, corporatiuns, and individuals interested in SPS activities and work.

Certain specifir groups in this counliy and abroad are quite knowledgeable about the SPS. At lenst two haliunal engineering associations, representing 200,000 members in electrical, electronics, aerospace, and systems disciplines, have run articles on the SPS in their journals.61 The SPS hao beein lie subject of several presentations at meetings of the Royal Aeronautical Society and the International Astronautical Federation in the last few years.

The question was generated in the Public Outreach Experimenr spnnsored by the Projecl orflice. In this experiment, summaries of twenty SPS reports were mailed to 9,000 recipients associated with the three public interest groups: Citizens Energy Project, Forum for the Advancement of Students in Science and Terhnolugy, and the L-'J Suclecy. Uver 1,000 responses have been received from these mailings.

${ }^{60}$ Group of closely interactive utilities, usually geographically cuntlguous.

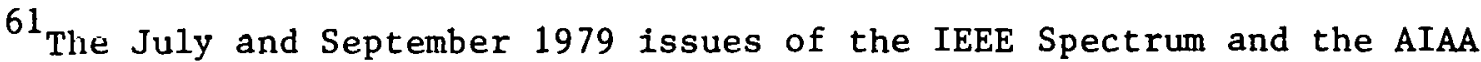
Position Paper of November 20, 1978. 
The national news media have also featured reports on SPS for the general public. The MacNeil/Lehrer Report had a nationally televised discussion of the pros and cons of the SPS on June 14, 1978. Several articles have appeared in the Los Angeles Times and the New York Times.

Finally, the Project office responds affirmatively to every request for information and operates under a policy of openness and accessibility.

IV.12 What constituencies are being studied for their probable response to the SPS?

There are no constituencies being studied, per se. Three groups the Citizens Energy Project, the L-5 Society and the Forum for the Advancement of Students in Science and Technology - are cooperating with Planning Research Corporation in eliciting comments from members on results of the SPS program and in establishing a dialogue between the Project office and these individuals. This dialogue serves several useful purposes. The Project Office can see if there are any concerns which are not being adequately addressed in the current assessment program. Furthermore, the questions which members of the three organizations pose enable the Project Office and the field staff to become more aware of the specific concerns people have about the SPS.

The Project Office has also funded a study by Rice University to place the SPS debate within a broad social and cultural milieu. The objective of the project is to identify and relate the sociocultural factors which shape the public acceptability of advanced technologies. The study will attempt to do this by reviewing the public debate over large-scale commitments of public funds for the development of the nuclear industry and other highly sophisticated technologies. Opinion poll data covering energy-related issues will also be analyzed.

The findings of these projects will be used by the Project Office to develop a continuing outreach program and to develop a process for long-term public involvement should the SPS program be continued.

V. ABOUT THE DOE PROGRAM

V.1 Why is DOE even involved in the evaluation and development of the SPS? Why isn't the private sector doing this on its own?

The concept of generating large amounts of electric power using satellites in space and transmitting it to earth originated in the private sector. A.D. Little's Peter Glaser first suggested the idea in 1968. The private sector has continued to follow development of the concept with interest. Public sector involvement in SPS investigation started relatively recently. The SPS is a long-term, large-scale venture, and has the promise to make a major impact on this nation's energy supply and economic situation if proven safe, and feasible technically and economically. This provides the basis for DOE interest. The DOE has supported a program to evaluate the SPS concept since 1976. 
The major U.S. aerospace companies have taken an active interest in the SPS concept since it was first proposed, and have continued to support independent work on SPS design studies. The Electric Power Research Institute, a private research organization funded by member utilities, is currently funding a study of SPS-utility integration issues. However, long-term investment in high-risk ventures demands a much more significant commitment by the private sector than is generally possible. Note, for example, federal government involvement in encouraging the commercialization of distributed energy systems. Ball's discussion of the synfuels challenge to industrial decision-making is very pertinent: 62

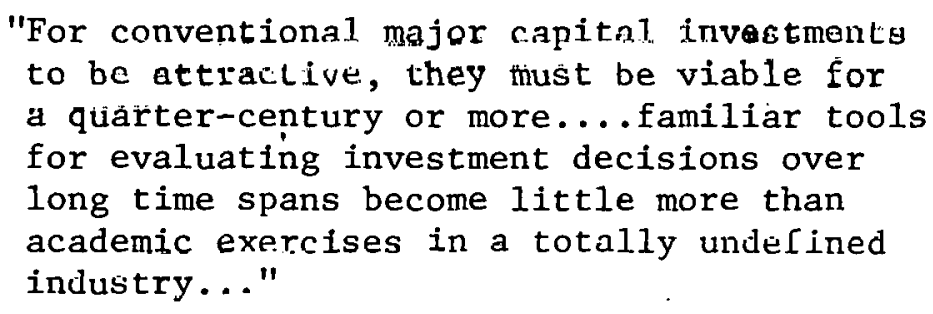

Space development ventures traditionally have been economically risky, and supported by federal financing. Once the technical and economic viability of a system has been demonstrated, the private sector has stepped in to develop the market. This was true for communications satellites, and will probably be true for the SPS. Therefore, it is likely that the major source of funds to support continued SPS evaluation will be the public sector, assuming the necessary policy decisions are made to proceed with the program.

V.2 Many respondents appear to believe that the objentive of the CDER erfort is to plan for the commercialization of the SPS. The actual objectives of the MOF. study are not clearly understuod. 'I'o what areas of investigation are the program funds being allocated? How much of the total is going to environmental studies?

The SPS Project Office's objective in undertaking the Concept Development and Evaluation Program (CDEP) is "to develop, by the end of 1980, an initial understanding of the technical feasibility, economic practicality, and the social and environmental acceptability of the SPS concept".63 The intent is to provide the gaversinumt and tlie American people with the information they need before deciding to

62 Ball, "New Challenges to Management in the Synfuels Revolution", Tcchnology Review, August/September 1979', pp. 34 and 35.

${ }^{63}$ Taken from a policy statement on the SPS issued by the Secretary of Energy. 
embark or not to embark, on the next stage of the SPS investigation. A decision to proceed would not result in commercial development of the SPS in 1980, but would result in implementation of a follow-on program, Ground Based Exploratory Development (GBED). This 7-9 year program would further reduce uncertainty about the SPS system design, its technical characteristics, and potential environmental and societal effects. The GBED would be followed by technical verification of the SPS if that were judged to be advisable.

\begin{tabular}{lr} 
CDEP Element & Funding \\
\hline Systems Definition & $\$ 6,600,000$ \\
Environmental Assessment & $6,500,000$ \\
Societal Assessment & $1,700,000$ \\
Comparative Assessment & $1,700,000$ \\
Emerging Technologies & $1,400,000$ \\
Analysis/Planning & $1,700,000$ \\
\multicolumn{1}{c}{ Total } & $\$ 19,600,000$
\end{tabular}

This table shows that about one third of the approximately $\$ 20$ million budgeted for the three-year CDEP program is allocated to defining the reference system. The remaining two-thirds is dedicated toward evaluation of the concept. The evaluation assumes implementation of the SPS in accordance with the reference system and asks: what is the environmental impact? How is society likely to be affected? How might it compare with alternate sources of energy? What alternative approaches might be used to obtain terrestrial power from satellites.

The Environmental Assessment will identify and assess environmental issues associated with the SPS reference system development and operation. These have been grouped into five general categories. Microwave health and safety effects account for about $30 \%$ of the budget; non-microwave health and safety about 10\%; atmospheric effects, ionospheric effects and electromagnetic compatibility (radio-frequency communication effects) each account for about $20 \%$ of the budget.

V.3 Just how much information on the SPS is available to the general public? Has such information appeared in the media? What agencies of the federal government have information that the public could obtain?

The Project office has encouraged inquiries about the SPS assessment it is conducting since the beginning of the program. Ail finished reports are available to the public through the National Technical Information Service (NTIS):

U.S. Department of Commerce

5285 Port Royal Road

Springfie1, VA 22161 
The Project Office also maintans an SPS Library, which is operated by the Argonne National Laboratory for the DOE. The Library has on file a limited number of copies of all current reports on the SPS and related topics. The Library periodically updates its bibliography of papers, reports, books and magazine articles on the SPS. Bibliographic inquiries should be directed in writing to:

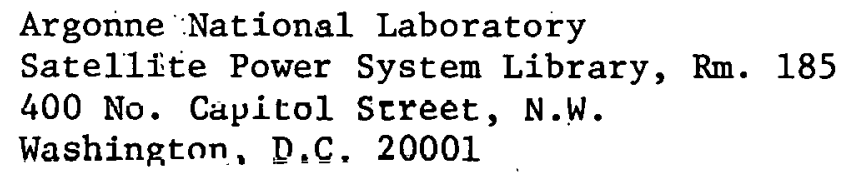

The pullle can àlso obtain copies of House and Senate hearings on the SPS. The hearings have included testimony from supporters and opponents of the SPS. In the House, the Science and Technology Subcommittee on Space Science and Applications has held hearings on the SPS on February 15, March 28-30 and May 2, 1979. The Senate Energy and Natural Resources Subcommittee on Energy Research and Development held a hearing on August 14, 1978. These committees may be contacted at the following addresses:

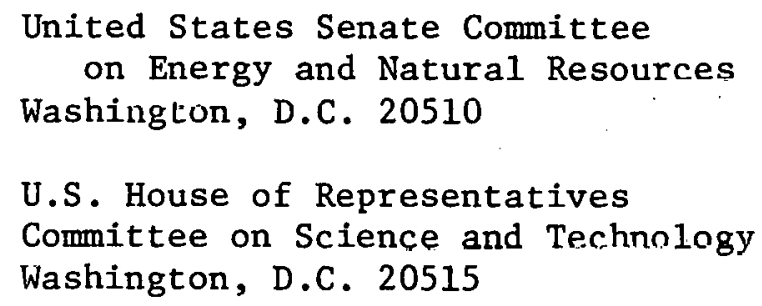

Occasional articles dealing with the SPS have appeared in newspapers and magazines. For example, the New York Times devored two pages to a review of the SPS concept in February 1979. The SPS concept has been referred to in articles dealing with space industrialization and space colonization in magazines having a national circulation, such as Fortune, Nation's Business, and Mother Jones. Mention of the SPS appeared in the national print media when President Carter enunclated his administration's space policy objectives and has continued in the coverage of the ensuing Congressional debates over Lhis policy. 
V.4 How realistic does DOE consider the SPS to be?

There has been a logical progression of growing interest in the SPS within the public and private sectors since the concept was first proposed by Peter Glaser in 1968. NASA considered the concept realistic enough to fund some SPS studies out of its "advanced studies" budget through FY76. Private corporations supported some small studies during this period, too. Congress also began to take notice of the SPS and in 1973 the first Congressional hearings of note took place. In early 1976, the Department of Energy (then, the Energy Research and Development Administration) established a Task Group on Satellite Power Stations to review past work and suggest future options.

After fiscal year 1976, the Office of Management and Budget transferred responsibility for SPS studies to ERDA (nOw DOE) since the SPS is basically an energy option. The Task Group found that the SPS showed sufficient promise to recommend a more detailed assessment in accordance with a defined set of activities. This recommendation formed the basis for the three-year Concept Development and Evaluation Program presently nearing completion. This program will provide the information from which a policy decision can be made to proceed further or not, and if so, at what pace.

The DOE, therefore, considers the SPS to be realistic enough to have undertaken a rather extensive concept development and evaluation program designed to determine what is known and unknown about the system and its potential impacts. The policy decisions to be made later this year will indicate how realistic the DOE considers SPS to be at that time.

V.5 On what does success of the SPS depend? How much will it cost to decide whether or not to go ahead with the SPS?

The success of the SPS will ultimately depend on its proven ability to provide baseload electric power safely and economically. Such an achievement could be met only with the successful completion of a series of programs designed to evaluate, and if recommended, to fully address technical, environmental and societal issues.

The three-year Concept Development and Evaluation Program, CDEP, nearing completion, has been undertaken as the first step.64 The CDEP objective is to develop an initial understanding of SPS system requirements, technology goals and their feasibility; identify the system's enviromental and sorietal affects and their acceptability; and evaluate the SPS compared with alternative energy systems.

${ }^{64}$ SPS Concept Development and Evaluation Program Plan, July 1977August 1980, DOE/ET-0034, February 1978. 
The CDEP has been designed to identify any major SPS problems and their magnitude, and determine whether these would foreclose the SPS option, or could be resolved through additional study, system design changes, or mitigation procedures. Integrated results of the CDEP study will provide information from which an informed decision to either terminate the program, or continue it in accordance with a defined option, can be made. Such a decision will have cost approximately $\$ 20$ million.

If no "program stoppers" are identified in the CDEP (none have been identified to date) a Ground Based Exploratory Development Program (GBED) could succeed it if the appropriate policy decision is made. The seven to nine year GBED program would consist of ground based experiments and exploratory research investigating the reference system and alternative systems and subsystems.

The GBED objective is to reduce uncertainty about SPS feasibility and viability to the point where an informcd decision could be made regarding initiation of an even more intensive research and development program leading to prototype components, on-orbit testing, and verification of the required technology: The costs of the GBED program, which would start in 1981, have not yet been estimated but will exceed CDEP costs by at least an order of magnitude.

V.6 Can energy self-sufficiency be arrived at through the SPS?

Clearly, no single energy technology will solve our energy problem. However, the SPS, working in concert with a mix of othcr Eyotcms, could make us less reliant on non=renewahte energy cources and hclp the U.S.: become more energy self-sufficient.

In 1976, the U.S. consumed 74 quadrillion Btu ${ }^{65}$ ( 1 quadriition $=$ 1000 trillion), or the Btu equivalent value in petroleum (including oil and gasoline), coal, electricity, and other energy forms. Fortyseven percent of all energy consumed was supplied by petrolcum; $27 \%$ by natural gas; about $19 \%$ by coal; hydropower and nuclear energy supplied about $4 \%$ and $3 \%$ reepectively. Although cnergy cunsumpeion is discributed more or less evenly by the four main end use energy sectors, energy supplies vary widely by end use sector. 66

65 The British thermal unit, Btu, is used as a measure of energy. One $B t u=$ the quantity of heat required to raise the temperature of 1 pound of water 1 degree Fahrenheit at standard atmospheric conditions.

${ }^{66}$ Energy Information. Handbook, Congressional Research Service; prepared for the House Interstate and Foreign Commerce Subcommittee on Energy and Power, July 1977. 


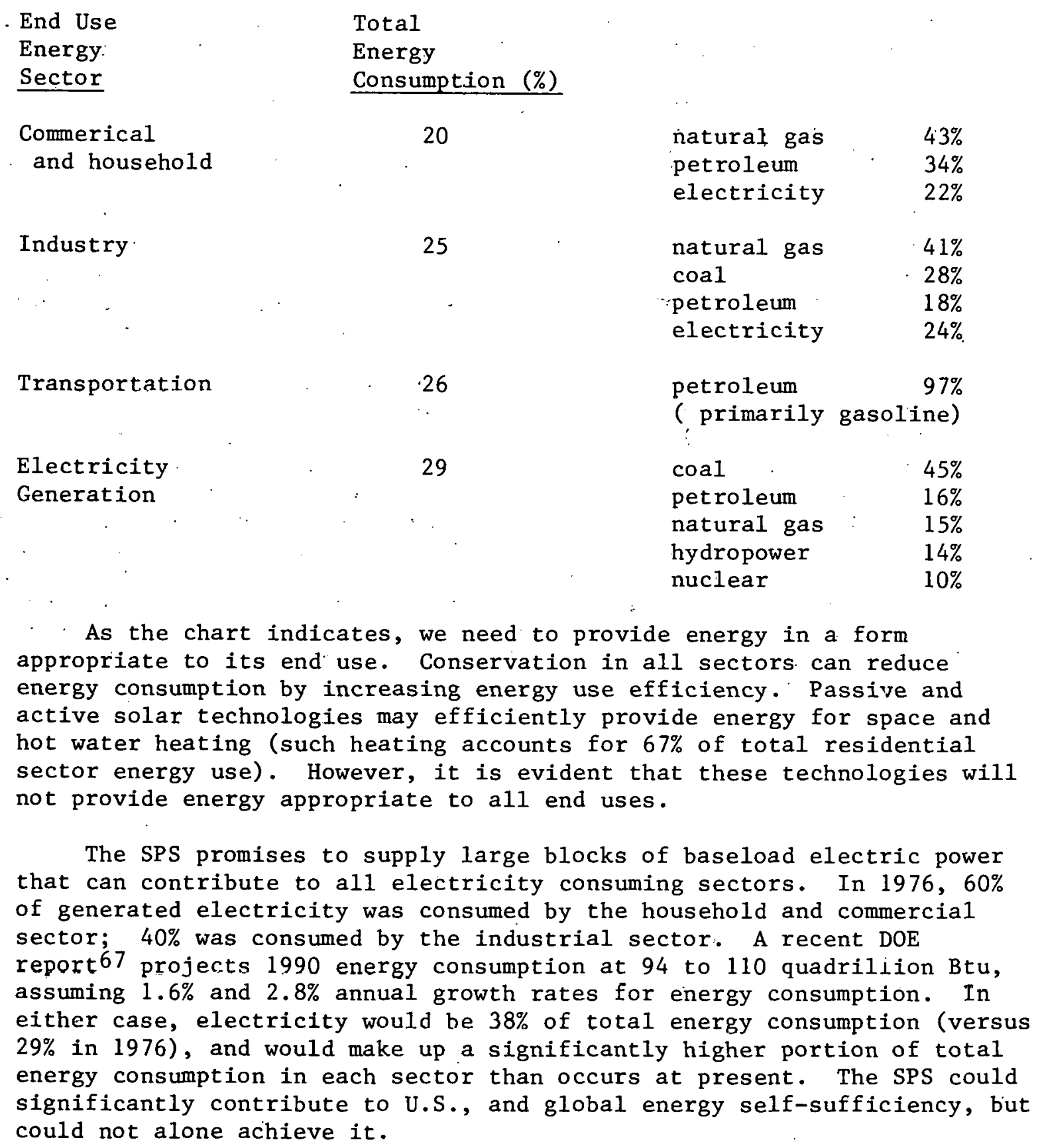

End Use

Energy

Commerical

and household

Industry

$\cdot 26$

29 natural gas $\quad 43 \%$

natural gas

coal $28 \%$

petroleum $\quad 18 \%$

2

( primarily gasoline)

coal . $45 \%$

petroleum $16 \%$

natural gas : $15 \%$

hydropower $\quad 14 \%$

nuclear $\quad 10 \%$ petroleum $\quad 34 \%$

As the chart indicates, we need to provide energy in a form appropriate to its end use. Conservation in all sectors can reduce energy consumption by increasing energy use efficiency. Passive and hot water heating (such heating accounts prov $67 \%$ of total residential sector energy use). However, it is evident that these technologies will not provide energy appropriate to all end uses.

The SPS promises to supply large blocks of baseload electric power that can contribute to all electricity consuming sectors. In $1976,60 \%$ of generated electricity was consumed by the household and commercial sector; $40 \%$ was consumed by the industrial sector. A recent DOE report67 projects 1990 energy consumption at 94 to 110 quadriliion Btu, assuming $1.6 \%$ and $2.8 \%$ annual growth rates for energy consumption. In either case, electricity would be $38 \%$ of total energy consumption (versus $29 \%$ in 1976), and would make up a significantly higher portion of total energy consumption in each sector than occurs at present. The SPS could could not alone achieve it.

67 Energy Supply and Demand in the Mid-Term: 1985, 1990, and 1995, DOE/EIA-0102 Order No. 476, April 1979. 
V.7 Does the DOE believe that SPS development will reinvigorate the U.S. internally and give it a renewed position of leadership abroad?

The DOE's current interest is in determining the practicality of the SPS concept as an energy source. It is premature, and probably wrong, to assume that the development of the SPS alone would provide the lasting and profound impact on society that the question suggests. This is especially so when one considers the array of technical, environmental and societal problems which must be solved prior to assuming such a vast undertaking. However, the SPS, if it is to be built at all, may well be just one part of a reinvigorated program of space application and research that would enhance U.S. prestigc on a worldwide basis.

Developments associated with transportation to space, space manufacturing and assembly and construction of large space structures are areas where technological leadership would be developed. The broad spectrum of technological challenges to implementing the SPS program might well keep the U.S. on the cutting edge of the technological advance for many years. SPS development would also provide an opportunity for significant international cooperation in exploring and exploiting the benefits of outer space and its resources. More importantly, perhaps, SPS development would provide badly needed energy to many countries of the globe with consequences that must on balance be beneficial, but largely unpredictable in terms of impact on the U.S. 
I. About the System

1. How stable will an orbiting satellite the size of the

SPS be at GEO or could it de-orbit like Skylab, posing

a danger to people on the ground?

2. How vulnerable is the SPS to partial or total. destruction, especially the space segment? For example, do meteor showers pose any threat to the space segment?

3. Is there a way that rivals, unauthorized personnel, etc. can gain control of SPS?

4. What is the basis for the claim that the satellites will have a 30 year lifetime?

5. Have maintenance requirements been considered in the analysis of the reference system concept? How would maintenance be performed?

6. Will new life-support systems be required for space construction crews or is present technology sufficient?

7. What are the manpower and training requirements to build the satellite?

8. How ohould today's students be preparing themselves in terms of training and education so as to have a greater opportunity for more direct involvement. in any future SPS undertaking?

9. Which is the cheaper reference system design - Rockwell's or Boeing's?

10. Is the DOE considering alternative reference system concepts? If so, how much money is being allocated for these studies relative to the current reference design?

II. About the Comparative Analysis

1. Will there be a comparative analysis of the SPS with alternate energy technologies?

2. Has a net energy analysis been done which compares the SPS with alternative energy technolgies? 
3. How much disruption of human settlement patterns and wild

lands will the SPS rectenna system create in comparison to coal and oil shale fuel cycles?

4. Would the SPS be functional soon enough to obviate massive coal and oil shale exploitation or do the timeframes for utilization of these alternative technologies, and attendant environmental impacts, overlap?

5. Would a breakthrough on fusion obviate the need for SPS? What forms and amounts of energy would fusion energy replace that wuld reduce, the need for SPS?

6. Wouldn't a breakchrough in terrestrial solar terhnologies reduce or eliminate the need for SPS? In particular; wouldn't advances in photovoltaics benefit terrestrial applications to the point where the SPS would be obsolete or comparatively uneconomical?

7. What impact will development of the SPS have on the labor market compared to alternate energy endeavors - will it be labor-intensive or capital-intensive?

III. About the Environmental Effects

1. A prominent concern is the microwave bio-effects. Some people want to know what happens to people and ecosystems near the rectenna should control of beam directionality be lost.

2. What are the atmospheric heating effects of decentralized. solar energy. systems compared to the SPS?

3. Will the SPS danage the ozone layer and create a "greenhouse" effect by heating "1 the atmoephcrc?

4. Why have only two years been allotted for atmospheric impact studies?.

5. Will communications systems alrcady in place be d13rupted by SPS operations?

6. Would the current SPS reference system design create significant additional conflict over utilization of the geostatinnary orbit?

7. How will SPS's in GEO affect the aesthetics of the night șy? 
8. Have psychological factors affecting manned operations in the space environment been taken into account in studies of the health and safety of the space workers?

IV. About the Societal Effects

1. Why do we need centralized power (baseload poweri) and a

national energy grid? Wouldn't a system like SPS require too much control over people, and large institutions to manage it? Many people have expressed a desire to be more self-reliant through control of their own energy supply. Wouldn't reliance on the SPS inhibit this goal?

2. How could SPS development lead to de-centralization of social institutions and decision-making structures?

3. What are the opportunity costs of developing the SPS? Won't the diversion of. so much capital to the SPS rob other promising energy technologies of development funds and leave the nation less flexible. in responding to energy needs. What does the country do for its energy while it waits for the SPS to come on-line?

4. Who will be the economic beneficiaries of the SPS? The impression is that only aerospace companies and their workers will benefit.

5. Who will provide insurance for the SPS? For damage claims from occupation exposure, wandering beams and crashes a la Sky Lab?

6. There is uneasiness over the whole issue of the military implications of SPS. Some people fear or suspect that its primary purpose is as a military weapon and wonder why such studies are"being done in the first place. Others wonder how vulnerable the system is to sabotage (especially the rectenna) and therefore to disruption in the supply of energy.

7. Will development of the SPS seriously deplete any of the earth's resources?

8. Have other countries been approached to participate in SPS studies? If so, which ones?

9. Who would control, maintain and provide funds for SPS development? 
10. Is a disruption of SPS power 1ikely? What happens to an area which derives some or all of its energy from an SPS should such an event occur?

11. Is there any public awareness of the SPS as a major candidate for long-term energy generation?

12. What constituencies are being studied for their probable response to the SPS concept?

V. About the DOE Program

1. Why is DOE even involved in the evaluation and development of the SPS - why isn't the private sector doing this on its own?

2. Many respondents appear to believe that. the objective of the CDEP effort is to plan for the commercialization of the SPS. The actual objectives of the DOE study are not clearly understood. To what areas of investigation are the program funds being allocated? How much of the total is going to environmental studies?

3. Just how much information on the SPS is available to the general public? Has such information appeared in the media? What agencies of the federal government have information that the public could obtain?

4. How realistic does DOE consider the SPS to be?

5. On what does success of the SPS depend? How much will it cost to decide whether or not to go ahead with the SPS?

6. Can energy self-sufficiency be arrived at through the SPS?

7. Does the DOE believe that SPS development will reinvigorate the U.S. internally and give it a renewed position of leadership abroad? 
United States

Department of Energy

Postaye and Fees Paid

U.S. Department of Energy

DOE. 360

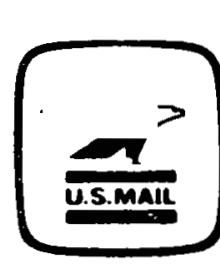

Washington. DC 20585

\section{FIRST CLASS MAIL}

OHicial Business

Penaity for Privato Uso, $\$ 300$ 